\title{
Okul Öncesi Öğretmenlerinin Algılarına Göre Çocuklarda Öz Disiplin Gelişimi: Uzun
}

\section{Bir Yol*}

\section{Asiye PARLAK RAKAP ${ }^{* *}$}

Öz: Mevcut çalışma, okul öncesi öğretmenlerinin çocuklarda öz disiplin gelişimi hakkındaki algılarına ulaşmayı amaçlamıştır. Bu amaca ulaşmak için vaka incelemesi nitel araştırma yöntemi izlenmiş ve Türkiye'deki özel bir eğitim kurumundaki durum ele alınmıştır. Kurumda yedi anaokulu öğretmeni çalışmaktadır. Veri toplama aracı olarak on kısa öykü ve ilgili soruları ile on bir görüşme sorusu içeren bir görüşme protokolü kullanılmıştır. Görüşme protokolü, okul öncesi eğitim kurumlarında araştırmacının yaptığı gözlemlerden sonra geliştirilmiş ve pilot çalışma sonrasında yeniden düzenlenmiştir. Veri analizi için betimsel analiz tekniği kullanılmıştır. Elde edilen sonuçlara göre, katılımcı okul öncesi öğretmenleri öz disiplinin ne olduğu, önemi, öz disiplini teşvik edecek olası ve uygun stratejiler hakkında bilgi sahibidir. Ancak öz-disiplin öğretmenler tarafından çocukların günlük yaşamlarında önemli olarak algılanmasına ve kendi rollerini tanımlamalarına rağmen, öz-disiplinle ilgili olmayan bazı vurgular ve literatürle uyumlu olmayan uygulamaların olduğu bulunmuştur. Gelecekteki araştırmalarda öz-disiplinle ilgili olmayan vurguların analiz edilmesi ve uygun uygulamaların geliştirilmesi önerilir.

Anahtar Kelimeler: Öz disiplin, okul öncesi öğretmenleri, ilk y1llar

\footnotetext{
${ }^{*}$ Bu çalışma, yazarın 2020 y1lı öncesinde tamamlanan In-service early childhood teachers' perceptions about their roles in the development of self-discipline in children başlıklı doktora tez çalışmasının bir kısmından üretilmiştir. ** Dr Öğr. Ü. Van Yüzüncü Y1l üniversitesi, Eğitim Fakültesi, Temel Eğitim Bölümü, Okul Öncesi Eğitimi ABD, Orcid ID: 0000-0001-8315-8628 E-posta: asiye.parlak@gmail.com.
}

\begin{tabular}{lll}
\hline Gönderim:18.02.2021 Kabul:18.03.2021 & Yayın:25.04.2021
\end{tabular}




\title{
Development of Self Discipline in Children According to Preschool Teachers' Perceptions: A Long Way
}

\begin{abstract}
Current study sought to reach preschool teachers' perceptions about self-discipline development in children. In order to reach this aim, case study research methodology was followed and a case in a private education institution in Turkey was handled. There were seven preschool teachers working at that institution. For data collection, an interview protocol, including ten vignettes with related questions and eleven interview questions was used. The interview protocol was developed after observations and revised after pilot study. For data analysis, descriptive analysis technique was used. According to the results, participant preschool teachers had some knowledge about what self-discipline was, its importance, possible and appropriate strategies that foster self-discipline. Despite perceiving it as crucial in everyday lives of children and describing teachers' important role, it was found that there were some unspoken aspects and irrelevant practices. Further research might analyze those aspects and develop appropriate practices.
\end{abstract}

Keywords: Self-discipline, preschool teachers, early years

\section{Giriş}

Hayatımız boyunca pek çok sınırla karşılaşırız. Bu sınırları tanıyarak çözmeye çalışmamız ya da bu sınırların farkında olup içerisinde kendi yolumuzu bulmamız çaba ve zaman gerektirir. Küçük yaştaki çocuklar için de durum benzerdir. Başlangıçta, sınırları deneyerek keşfetmeye; bu keşif esnasında ise kabul edilebilir olanı anlayarak kendi sınırlarını belirlemeye çalışırlar. Bu aşamada çevrelerindeki insanların ilgisini çekmek için çeşitli davranışlar sergilerler. İlgi çekmek için kullandıkları bu yollar yetişkinler tarafından istenmeyen davranış kategorisinde değerlendirilebilir (Cummings, 2000; Curwin \& Mendler, 1999; Edwards, 2000) ve zaman zaman onları kızdırabilir. Uygun olan davranışı bulmaya çalışmaları, daha önceden farkında olmadıkları sınırları fark etmelerini sağlar; deneyimleri ve aldıkları tepkilerle de bu sınırları içselleştirirler (Bear, 2005). Çocuklar bunlara ek olarak, sınırlarını bulabilmek için sınıf ortamında da pek çok denemeler yaparlar. Çocukların denemelerini küçümsemek, öğretmenlerin tüm çocukların yanlış davrandıklarını düşünmelerine ve çocukları disiplin altında tutmak için en iyi yolu aramalarına yol açar (Cummings, 2000; Curwin ve Mendler, 1999). Araştırmacılar, gözlemciler, öğretmenler veya ebeveynler (yaşlılar) çocukları disipline etmenin en iyi yolunu bulmak için çalışmaktadırlar. 
Böylece farklı noktalara vurgu yapan farklı disiplin modelleri geliştirilmiştir. $\mathrm{Bu}$ disiplin modelleri, önleyici veya düzeltici olduğu kadar, davranışçı veya gelişimsel temele sahip olarak da kategorize edilebilir (Bear, 2005). Tüm bunlar, sadece yanlış davranışlarla başa çıkma açısından değil, aynı zamanda çocukların sonraki davranışlarının belirleyici faktörleri olması açısından da çok önemlidir (Şimsek, Ulukol ve Bingöler, 2004; Çocuk ve Aile Sağlığının Psikososyal Yönleri Komitesi [Committee on Psychosocial Aspects of Child and Family Health], 1998). Başka bir ifadeyle, çocukların istenmeyen davranışlarına yetişkinlerin verdikleri tepkiler çocukların gelişmekte olan karakterleri üzerinde etkiye sahiptir. Bu etki, içsel veya dışsal motivasyona sahip olma (Bear, GG, Slaughter, JC, Mantz, LS ve Farley-Ripple, E., 2017; Carlton ve Winsler, 1998 ; Gottfried, Fleming ve Gottfried, 2001; Gottfried ve Gottfried, 1996; Gottfried, Gottfried, Morris ve Cook, 2008), öz kontrol geliştirme (Duckworth ve Carlson, 2013; Duckworth ve Gross, 2014; Eisenberg vd., 2009; Mischel, 2014; Moffitt vd., 2011), öz düzenleme becerilerine sahip olma (Caseya vd., 2011; Willis, 2016), yürütücü işlevlere sahip olma (Diamond, 2012; Diamond ve Lee, 2011; Zelazo ve Carlson, 2012), öz disiplinli olma ya da olmama (Baerny, 2006; Duckworth ve Seligman, 2005; Goldman, 2006), vb. şeklindedir.

Çocukların gelişen karakterlerinden biri olan öz disiplin, karakterin önemli bir parçasıdır. Öz disiplin kavramı, kendi davranışlarının sorumluluğunu almak, diğer bir deyişle onları kontrol etmek olarak özetlenebilir (Tao, Wang, Fan ve Gao, 2014; Zimmerman ve Kitsantas, 2014). Günlük yaşamda oldukça önemli kabul edilmiştir (Tao, Wang, Fan ve Gao, 2014). 1906 Nobel Barış Ödülü'nü kazanan ve Amerika Birleşik Devletleri'nin 26. başkanı olan Theodore Roosevelt, öz-disiplinin önemine yıllar önce işaret etmiştir. Öz disiplini kalitenin anahtarı olarak tanımlamış, her şeyi mümkün kılmak için bir anahtar olarak kabul etmiştir (McDonald, Ekim 2015).

Öz disiplinin birçok tanımı yapılabilir (Bear, 2005) ve bu tanımlarla bağlantılı olarak öz disiplin ve diğer yapılar (motivasyon, öz denetim, öz denetim, yürütme işlevleri, denetim odağ vb.) arasında farklı bağlantılar bulunabilir (Balat, 2005; Bear, 2005; Gordon, 1991; Oktay, 2005). Bireysel ve sosyal yaşam üzerinde olumlu etkiler gösteren öz disiplin duygusal, sosyal ve ahlak gelişim alanı ile tanımlanmaktadır (Bear, 2005). Dolayısıyla öz disiplinin gelişimsel, destekleyici ve yönlendirici olduğu ve olması gerektiği söylenebilir. Bu ise toplumların çağlar boyunca öz disiplin stratejileri geliştirmeye önem vermelerinin nedeni olarak görülmektedir (Bear, 2005; Wiener ve Philips, 1971). 
Öz disiplin, olumlu bir okul iklimini akademik başarıyı geliştirerek ve öz-değerin gelişimini destekleyerek güçlendirir. Ek olarak, öz disiplinli bireylerin başkalarıyla rekabet ederken etik davrandıkları ve kişisel, sosyal veya akademik sorunları kendi kendilerine çözdükleri vurgulanmaktadır. Ayrıca, öz disiplinin yaşamın ilk yıllarından itibaren geliştirilebileceği kabul edilmektedir (Bear, 2005; Coloroso, 2002).

\section{Ülkemizde okul öncesi eğitimin durumu}

Erken çocukluk yıllarının karakter üzerindeki önemli ve geri döndürülemez etkileri, sosyal ve beşeri bilim toplulukları tarafından yıllardır kabul edilmektedir. Erken çocukluk dönemi ve eğitimi, Türk toplumu ve kurumları tarafından giderek artan şekilde ilgi görmektedir. Türkiye'de Milli Eğitim Bakanlığı (MEB) ve Yüksek Öğretim Kurumu (YÖK) okul öncesi eğitimle ilgili uygulamaları planlamak ve yönlendirmekle sorumlu kurumlardır. Okul öncesi eğitim kurumlarında planlama için 2013 Okul Öncesi Eğitim Programı (MEB, 2013) kullanılmaktadır ve bu kurumlar, 3-6 yaş arası çocuklara hizmet vermektedir. 2013 Okul Öncesi Eğitim Programı okul öncesi eğitimin ilkeleri, günlük eğitim akışı şablonu, etkinlik planı şablonu ve aylı plan şablonunun yanı sıra ölçme ve değerlendirme bölümleri gibi planlama ilkelerini içermektedir. Programda disipline odaklanmak yerine, etkili sınıf yönetimi stratejileri (örneğin, çocuk merkezli planlanmış etkinlikler) vurgulanmaktadır. Ayrıca, eğitim fakültelerindeki Okul Öncesi Öğretmenliği programları Yüksek Öğretim Kurumu tarafindan planlanmakta ve takip edilmektedir. Bu programda Sınıf Yönetimi adında bir ders bulunmaktadır. Derste ele alınan konular her ne kadar sınıf, öğretmen, sınıf yönetimi ve disiplin modelleri, motivasyon, liderlik, zaman yönetimi, iletişim olsa da öz disiplin konusunda çok az (disiplin modelleri tartışılırken) veya neredeyse hiç bir bilgiye yer verildiği görülmektedir. Buna dayanarak, mevcut çalışmada okul öncesi öğretmenlerinin çocukların öz disiplin, öz disiplinin önemi ve öz disiplin gelişimindeki rollerine ilişkin algıları ve öz disiplin gelişiminde etkili olduğunu düşündükleri teknikler analiz edilmeye çalışılmıştır. Bu nedenle, bu çalışmanın amacı, okul öncesi öğretmenlerinin çocukların öz disiplin gelişsimindeki rollerini nasıl algıladıklarına ulaşmaktır. Bu amaçla ilgili olarak aşağıdaki sorular araştırılmıştır:

- Okul öncesi öğretmenleri öz disiplini nasıl tanımlıyor?

- Okul öncesi öğretmenleri öz disiplinin önemini nasıl algılıyor?

• Okul öncesi öğretmenleri öz disiplinin gelişiminde kendi rollerini nasıl tanımlıyor?

\section{Yöntem}

Eğitimde takip edilen bilimsel araştırmalardan biri olan nitel araştırma deseni, var olan bir duruma, olguya, vb.ne yönelik derin anlamlar aramada etkilidir (Creswell, 2007). Bu 
çalışmada, hizmet içi okul öncesi öğretmenlerinin deneyimlerine göre öz disiplini nasıl algıladıklarına ulaşılması amaçlanmıştır. Bu nedenle, bu çalışmada nitel araştırma deseni kullanılmıştır.

Farklı görüşlere sahip olan nitel desen, farklı araştırma yöntemlerine sahiptir. Bu nitel araştırma yöntemlerinden biri olan vaka çalışması bağımsızdır; tanımlayıcı bir biçime sahiptir ve araştırmaya sezgisel olarak yaklaşır (Merriam, 1998). Ek olarak, vaka çalışmasında araştırma süreci, önceden bilinenlere yeni bilgiler eklemeye yardımcı olur ve böylece var olan bilgiyi genişletir (Merriam, 1998; Yin, 2009). Bu çalışma için öz disipline ilişkin okul öncesi öğretmenlerinin algıları anlaşılmaya çalışılmıştır. Vaka çalışması, bilgiyi getiren ve genişleten bir tasarım olduğu için mevcut çalışmada bu yöntem takip edilmiştir.

Bir hikâyenin, bir filmin veya bir romanın güçlü kısımları, bağlam ve durumların yanı sıra içerik ve bunların ilişkisinin tanımlarıdır. Bağlam, durum, içerik ve her üçü arasındaki ilişki, nitel araştırma deseninin de anahtarlarıdır (Stake, 2010). Bu nedenle; katılımcılar, veri toplama araçları, veri toplama süreci ve veri analizi oldukça önemli hale gelir.

\section{Araştırmanın bağlamı ve katılımcılar}

Araştırmanın katılımcıları, Ankara'daki özel bir eğitim kurumunda okul öncesi öğretmeni olarak çalışan yedi kadın öğretmendir. Öğretmenlerin hepsi 30 yaşın altındadır; bitirdikleri son okul bir eğitim fakültesinin okul öncesi öğretmenliği programıdır ve bir ile altı y1llık öğretmenlik tecrübeleri bulunmaktadır.

Eğitim kurumu şehir merkezine uzaktır. Çocuklar oraya okul servisi veya ebeveynlerinin araçlarıyla ulaşabilirler. Öğretmenler çocuklara okul servislerinde eşlik edebilir veya okula başka bir ulaşım firsatıyla gidebilir. Hangi seçeneği tercih ederlerse etsinler, ya çocuklar gelmeden önce ya da çocuklarla birlikte sınıfa ulaşırlar; çocuklardan geç gitmezler. Okul bir tam gün boyunca, yaklaşık 8.30 ile 17.30-18.00 arasında hizmet verir. Bu nedenle; kahvaltı, öğle yemeği ve ikindi atıştırmalıkları okul tarafindan sağlanır ve öğretmenler çocuklara öğünlerinde mutlaka eşlik eder. Bu kurum, bir anaokulu bölümü, bir ilkokul bölümü ve bir ortaokul bölümü içeren kapsamlı bir eğitim kompleksidir. Bu eğitim kompleksinin anaokulu bölümünde sosyal ve akademik çalışmalar için çeşitli, altı yaş grubu için dört ve beş yaş grubu için bir sınıf/lar bulunmaktadır. Her sınıfta üniversite mezunu iki öğretmen görev yapmaktadır. Eğitim kadrosunda aynı zamanda eğitim koordinatörü ve eğitim uzmanları yer almaktadır. Dersler hem planlama hem de uygulama süreçlerinde çocuk merkezli ve gelişimsel olarak uygundur. Ayrıca anaokulları için bir disiplin ve okula hazırlık politikası bulunmaktadır.

\section{Veri toplama aracı}


Veri toplama için bir görüşme protokolü geliştirilmiştir. Görüşme protokolü, özel iki anaokulundaki gözlemlere ve ilgili literatüre dayanarak oluşturulmuştur. Yapılan gözlemlerde öğretmenlerin farklı etkinliklerdeki öz disiplin geliştirme ve öğretmen-çocuk etkileşimlerine ilişkin davranışları kaydedilmiştir. Her iki kurumda da on iki hafta boyunca (haftada bir saat) olmak üzere altı yaş sınıfında gözlem yapılmış; anekdot kayıtları alınmış ve ardından bu anekdotlar içerik analizi tekniğiyle analiz edilmiştir. Analiz sonucunda dört tema (karakter, özerklik, öz kontrol ve sorumluluk) ve bu temalarla ilişkili on kod (uygun davranma, başkalarına saygı gösterme, dürüst olma, işi bitirme, sıraya girme, sırasını bekleme, işbirliği yapma, bağımsız çalışma, öfke yönetimi ve sorumluluk alma) belirlenmiştir. Görüşme protokolü böylece, bu analiz sonucunda belirlenen ve her biri üç ile dört sorudan oluşan on vinyet ve on bir görüşme sorusundan oluşacak şekilde düzenlenmiştir.

Vinyetler, bir kişinin ilgilendiği bir konuda tutum, inanç ve algılarını edinmeye yardımcı olan (Barter ve Renold, 2000; Hughes ve Huby, 2002; Schoenberg ve Ravdal, 2000; Stolte, 2001) ve kişinin bu konudaki olası eylemi veya davranışını yansıtan (Barter ve Renold, 2000; Jeffries ve Maeder, 2004-2005) etkili araştırma araçlarıdır. Bu nedenle; okul öncesi öğretmenlerinin sınıflarında öz disiplin geliştirmeye yönelik olası eylem ve davranışlarına ulaşmak için her biri bir gözlem veri analizi koduna dayalı on kısa vinyet geliştirilmiştir. Bağlam, bireyler ve varsayımsal bir senaryo, katılımcının bakış açısını elde etmek amacıyla bir vinyet geliştirmek için gerekli araçlardır (Barter ve Renold, 2000; Hughes ve Huby, 2002; Jeffries ve Maeder, 2004-2005; Schoenberg ve Ravdal, 2000). Bu nedenle, araştırma kapsamında geliştirilen her vinyetin bir bağlamı, karakterleri ve senaryosu vardır. Vinyetlerin kelime sayısı 114 ile 272 arasında değişmektedir. Cinsiyet önyargısını önlemek için her iki cinsiyete uyan karakter isimleri kullanılmıştır. Her vinyet sunumunu üç ile dört ilgili soru izlemektedir ve bazı ek araştırma sorusu sorulmuştur. Vinyetlere ek olarak, katılımcıların bakış açılarını almak için on bir görüşme sorusu oluşturulmuştur. Görüşme soruları üç aşamalıdır: okul öncesi sınıfındaki sıradan bir gün, etkileşimler ve gözlemlenen yanlış davranışlar ve öz disiplin gelişimini hissetme ve kabullenme. Görüşme protokolü geliştirildikten sonra vinyetlerdeki akış ve görüşme sorularının uygunluğu, iki uzman okul öncesi öğretmeni tarafından değerlendirilmiştir.

Çalışma öncesinde, görüşme protokolünün uygunluğu altı okul öncesi öğretmeniyle yapılan görüşmelerle test edilmiştir. Öğretmenlerden üçü devlet anaokulunda çalışırken diğer üçü Ankara'da özel anaokullarında çalışmaktaydı. Pilot çalışma verilerini analiz etmek için içerik analizi kullanılmıştır. Ortaya çıkan dört tema (öz disipline ilişkin tanımlar, öz disiplinin 
görevleri, öz disiplinin önemi ve öz disiplin geliştirme stratejileri), alt temalar, kodlar ve alt kodlardan oluşan bir kodlama sayfası oluşturulmuştur.

$\mathrm{Bu}$ süreçlerden sonra on vinyet ve on bir görüşme sorusundan oluşan görüşme protokolüne son şekli verilmiştir. Tüm vinyetler bir bağlam, bireyler ve gözlemlere dayanan varsayımsal bir senaryo içermektedir. Vinyetler anlatıldıktan sonra 3-4 soru etrafında bir konuşma yapılarak öğretmenlerin konu ile ilgili davranışları alınmaya çalışılmıştır. Görüşme soruları ise onların öz disiplin hakkındaki görüşlerini almak için önemlidir. Bu nedenle, bu iki veri toplama aracı kullanılarak hem öz disiplin hem de çocuklarda gelişimine yönelik okul öncesi öğretmenlerinin algılarına ve olası davranışlarına ulaşılmış ve veri analiziyle yansitılmıştır.

\section{Veri toplama süreci}

Veri toplama sürecinde yarı yapılandırılmış görüşmeler planlanmıştır. Veriler, veri toplama aracında bahsedilen bir görüşme protokolü aracılığıyla toplanmıştır. Görüşme yapılan ortamların sessiz olmasına özen gösterilmiştir ve ortamlar katılımcının uygunluğuna göre farklılaşmıştır. Görüşmeler okulda, evde veya sessiz bir kafede bire bir ve yüz yüze yapılmıştır. Görüşmeden önce görüşmeye davet ederken her katılımcıya görüşme hakkında kısa bir bilgilendirme aktarılmıştır. Görüşmenin başlangıcında ise katılımcılara çalışmanın amacı anlatılmış ve katılımcılar hakları konusunda bilgilendirilmişlerdir. Görüşmeler, katılımcı onamları alınarak başlamıştır. Katılımcı bir soruya cevap vermek istemediğinde o soru atlanmış ve bir süre sonra aynı soru hatırlatılmıştır. Bu soru üzerinde konuşmayı kabul ederse, cevap not edilmiştir. Ek araştırma soruları kullanılarak katılımcının kendisini rahat hissetmesi sağlanmaya çalışılmış, süreçte yansıtıcı dinleme uygulanmıştır. On vinyet ve on bir görüşme sorusunun yer aldığı görüşme protokolünün uygulanmasında her görüşme en az bir buçuk saat sürmüştür. Pilot çalışmadan elde edilen deneyime dayanarak, katılımcılar görüşmenin ortalama ne kadar süreceği konusunda başlangıçta bilgilendirilmiştir. Veri toplama sırasında katılımcıların izinleri ile bir ses kayıt cihazı kullanılmış ve kayıtlar her görüşmeden sonra kelimesi kelimesine yazıya dökülmüştür.

\section{Veri analizi}

Veri analizi, birkaç aşamalı bir sarmal izlenerek yapılmıştır. Adımlar şu şekildedir: verilerin yönetilmesi; okuma ve not alma; açıklama-yorumlama ve sınıflandırma yapma; temsil etme ve görselleştirme (Creswell, 2007). Üçüncü adımda betimsel analiz tekniği kullanılmıştır. Veri analizi için pilot çalışma sırasında geliştirilen kodlama sayfası kullanılmıştır. 
Araştırmanın güvenilirliği, kaynakların üçgenlemesi ve analiz edenler üçgenlemesi ile kontrol edilmiştir (Denzin, 1978, aktaran Creswell, 2007; Merriam, 1998; Patton, 2002). Vinyet ve görüşme sorularından elde edilen veriler, birinci tür üçgenleme amacıyla karşılaştırılmalı analiz edilmiştir. Vinyetlerle olası uygulamalar, görüşme sorularıyla da bakış açıları arasındaki uyuma bakılmıştır. İkinci tür için, bir kodlama bilgi sayfası oluşturulmuş, aynı üniversiteden ve aynı bölümden motivasyon, öz düzenleme ve nitel araştırma üzerine çalışan bir meslektaşla bu kodlama bilgi sayfası paylaşılmıştır. Pilot kodlama yapıldıktan sonra, meslektaş ile yedi öğretmenden ikisine ait veriler, yani verilerin \%30'u kodlanmıştır. Kodlayıcılar arası güvenilirlik aşağıdaki formül kullanılarak hesaplanmıştır: Aynı şekilde kodlanan toplam ifade sayısı / kodlanan toplam ifade sayısı*100. Yapılan karşılıklı değerlendirmelerde kodlayıcıların \%95 fikir birliğine ulaştığı tespit edilmiştir. Farklı kodlanmış kodları tartıştıktan sonra, güvenilirlik oranı \% 97'ye yükselmiştir. Uzlaşılamamış kodlar için ise, ilköğretim bölümünde deneyimli bir nitel araştırma uzmanına danışılmıştır.

Aktarılabilirlik için kapsamlı anlatım (Merriam, 1998) kullanılmıştır. Süreç açık bir şekilde aktarılmaya çalışılmış ve böylelikle herhangi bir okuyucunun, mevcut araştırmanın uygunluğu konusunda karar verebilmesi sağlanmaya çalış1lmıştır.

Mevcut çalışmanın her adımında katılımcılara hakları (örneğin ilgileri yoksa geri çekilme, görüşmeyi durdurma veya belirli bir soruyu cevaplamama) ve araştırmacıların bu hakları korudukları beyan edilmiştir. Ne sesleri ne de verileri üçüncü şahıslarla paylaşılmıştır. Kimliklerini belirleyecek bir bilgi verilmemiş ve adları yerine takma adlar kullanılmıştır. Bu takma adlar, Deniz, Ender, Hidayet, Ilgaz, Nimet, Tuna ve Ufuk öğretmen olarak ve cinsiyet ya da kimlik belirtmeyecek şekilde belirlenmiştir.

\section{Bulgular}

Yedi öğretmen ile görüşmeler yapıldıktan sonra veriler analiz edilmiş ve analiz sonucunda dört tema ortaya çıkmıştır. İlk iki tema (öz disipline ilişkin tanımlar ve öz disiplinin görevleri) ilk araştırma sorusuyla, üçüncü tema (öz disiplinin önemi) ikinci araştırma sorusuyla ve son tema (öz disiplin geliştirme stratejiler) üçüncü araştırma sorusuyla ilişkilidir. Her temanın ayrıca alt temaları, kodları ve alt kodları vardı.

\section{Okul öncesi öğretmenlerinin öz disiplin tanımları}

Katılımcılar öz disiplini (Tablo 1) tanımlarken bazı kavramlar kullanmışlardır. Bu kavramlar: kendini ifade etme (iki öğretmen), öz denetim (altı öğretmen), öz düzenleme (dört öğretmen), öz örgütlenme (üç öğretmen), ne yaptığını bilme (tüm öğretmenler), doğruyu 
yanlıştan ayırma (üç öğretmen), dışsal kontrol edilmeme (üç öğretmen) ve yetişkin denetiminin olmadığı durumlarda biri varmış gibi davranmadır (dört öğretmen). Erdem öğretmen yedinci görüşme sorusundan bahsederken öz disiplini özdenetim üzerine vurgu yaparak düşüncesini şöyle aktarmıştır: “Ben bunu hep bir şey olarak tanımladım: Her zaman öz disiplini kişinin kendi davranışını kontrol etmek olduğunu düşündüm, öz-içselleştirme, kendi kendine uygulama.. " Ufuk öğretmen, yedinci vinyeti tartışırken öz disiplinin dışsal olarak kontrol edilmeme olduğunun altını çizmiştir: "Böylece çocuk yukarıdan gelen hiçbir emri kabul etmeyecektir."

Tablo 1. Okul öncesi öğretmenlerine göre öz disiplinin tanımı

\begin{tabular}{ll}
\hline Öz Disipline İlişkin Tanımlar & \# katılımcı sayısı \\
\hline Kendini ifade etme & 2 \\
Öz denetim & 6 \\
Öz düzenleme & 4 \\
Öz örgütlenme & 3 \\
Ne yaptığını bilme & 7 \\
Doğruyu yanlıştan ayırma & 3 \\
Dışsal kontrol edilmeme & 3 \\
Yetişkin denetiminin olmadığı & 4 \\
durumlarda biri varmış gibi davranma & \\
\hline
\end{tabular}

Öğretmenlere göre öz disiplinin dört görevi vardır (Tablo 2): olumlu duyguların geliştirilmesi (tüm öğretmenler), ahlaki duyguların geliştirilmesi (tüm öğretmenler), başa çıkma becerilerinin geliştirilmesi (tüm öğretmenler) ve öz kontrolün geliştirilmesi (tüm öğretmenler).

Tablo 2. Okul öncesi öğretmenlerine göre öz disiplinin görevleri

\begin{tabular}{ll}
\hline Öz Disiplinin Görevleri & \# katılımcı sayısı \\
\hline Olumlu duyguların geliştirilmesi & 7 \\
Ahlaki duyguların geliştirilmesi & 7 \\
Başa çıkma becerilerinin geliştirilmesi & 7 \\
Öz kontrolün geliştirilmesi & 7 \\
\hline
\end{tabular}

Tüm öğretmenler olumlu duyguların gelişmesini öz disiplinin bir görevi olarak aktarmış ve bunlardan altısı deneyimlerini örnek vererek vurgulamıştır. Hidayet öğretmen bu görevi üçüncü vinyetteki şu sözleriyle ifade etmiştir: “Bu şekilde davranırsam kendi beden farkındalığını keşfeden bir çocuk için etiketlemek kendi bedeni için utanç verici olur. Amacımız elbette bunu önlemek, kendi bedenlerinden vb. utandırmamaktır." ve Deniz öğretmen ikinci 
vinyette bu görevi uygulamasıyla örneklendirmiştir: “Çocuk mutlu olacak çünkü yapmak istediği bir şey. Bazen sadece çocukların mutluluğu için bir şeyler yapabiliriz çünkü her zaman planlarla gitmek zorunda değiliz." Bunlara ek olarak, katılımcı öğretmenler olumlu duygular geliştirmenin yollarından bahsetmişlerdir (Tablo 3). Bunlardan bazıları; kendi davranışlarının sorumluluğunu almaya teşvik etme (beş öğretmen) ve çocuğu kendi performansını değerlendirmeye teşvik etme (üç öğretmen) gibi çocuğa yöneliktir. Birisi, başkalarından, özellikle ebeveynler ve akranlardan destek talep etme (beş öğretmen) şeklinde öğretmen ve çocuk dışındaki kişilerle ilişkilidir. Bazıları ise öğretmen davranışıyla alakalıdır. Öğretmen davranışıyla ilgili olanlardan bazıları öğretmenin tutumuna yöneliktir. Bunlar, sosyal destek sağlama (altı öğretmen); tüm çocukları koşulsuz kabul etme ve onlara koşulsuz özen ve saygı gösterme (tüm öğretmenler); sosyal karşılaştırmadan kaçınma ve disiplin sorunlarını ele alma (tüm öğretmenlere göre özel ele alma ve üçüne göre bazı durumlarda alenen yapma); çocuğun özerkliğine sayg1 göstermedir (tüm öğretmenler). Diğerleri ise öğretmenin ortam oluşturmasıyla ilgilidir: çocuklara sosyal aidiyet duygusunu deneyimlemeleri için uygun ortam sağlama (beş öğretmen) ve olumlu ve sevecen bir ortam oluşturma (tüm öğretmenler). Ufuk öğretmen sosyal destek sağlamaya dördüncü vinyette vurgu yapmıştır. Bu vinyette öğretmenin yapması gereken davranışa odaklanmış ve çocuğa yaklaşması, yakınına oturması ve çocuğun öğretmeninin orada, yakınında olduğunu hissetmesi için başına veya omzuna dokunması gerektiğini söylemiştir.

Tablo 3. Okul öncesi öğretmenlerine göre öz disiplinin birinci görevine ilişkin stratejiler

\begin{tabular}{|c|c|}
\hline $\begin{array}{l}\text { Öz Disiplinin Birinci Görevine İlişkin Stratejiler: } \\
\text { Olumlu duyguların geliştirilmesi }\end{array}$ & \# katılımc1 sayısı \\
\hline Kendi davranışlarının sorumluluğunu almaya teşvik etme & 5 \\
\hline Sosyal destek sağlama & 6 \\
\hline $\begin{array}{l}\text { Başkalarından, özellikle ebeveynler ve akranlardan destek } \\
\text { talep etme }\end{array}$ & 5 \\
\hline $\begin{array}{l}\text { Tüm çocukları koşulsuz kabul etme ve onlara koşulsuz } \\
\text { özen ve saygı gösterme }\end{array}$ & 7 \\
\hline $\begin{array}{l}\text { Sosyal karşılaştırmadan kaçınma: çocuğu kendi } \\
\text { performansını değerlendirmeye teşvik etme }\end{array}$ & 4 \\
\hline $\begin{array}{l}\text { Çocuklara sosyal aidiyet duygusunu deneyimlemeleri için } \\
\text { uygun ortam sağlama }\end{array}$ & 5 \\
\hline Disiplin sorunlarını özel ele alma & 7 \\
\hline Disiplin sorunlarını bazı durumlarda alenen ele alma & 3 \\
\hline Çocuğun özerkliğine saygı gösterme & 7 \\
\hline Olumlu ve sevecen bir ortam olusturma & 7 \\
\hline
\end{tabular}


Okul öncesi öğretmenlerine göre öz disiplinin ikinci görevi, ahlaki duyguların gelişimidir (Tablo 4). Hidayet öğretmen, bu alt temadan bir öğretmen ve iki çocuk hakkındaki ilk vinyet ile bahsetmiştir. Vinyetteki hikâyeye göre, çocuklardan biri özel bir çocuktur ve sınıfa kaynaştırma öğrencisi olarak katılmaktadır. Diğer bir çocuk, bir kitap okuma etkinliği sırasında özel çocuğa “deli” diye seslenir ve vinyete ilişkin soru öğretmenin olası ve uygun davranışıyla ilgilidir. Hidayet öğretmen, “O zaman tamam, tepkimi yumuşatayım ama o çocukla kesinlikle bireysel olarak diğer arkadaşının farklılıkları hakkında konuşacă̆ım, neden böyle, işte desteğimize daha çok ihtiyacı var gibi. Mesela ben bir iş sırasında ona arkadaşına yardımcı olma sorumluluğu veririm. Empati kuracă̆ından ve ona yardım edeceğinden eminim. Örneğin, bununla ilgili bir yaratıcı drama etkinliği planlayabilirim. " Empati becerilerinin (beş öğretmen) ve sorumlulukla ilgili becerilerin (dört öğretmen) geliştirilmesi bu alt temanın önemli yönleri olarak bulunmuştur. Bunlara ek olarak, katılımcılar empati becerilerini geliştirmek için başkalarının duygularına odaklanmanın rolüne; sorumlulukla ilgili becerilerin geliştirilmesi için sosyal sorumluluğa, sorumluluk vermeye ve ahlaki sorumluluğa vurgu yapmışlardır. İşbirliği yapma, farkındalık, başkalarını dinleme ve dürüst olma, bu alt temanın kodları ile ilişkili bulunmuştur.

Tablo 4. Okul öncesi öğretmenlerine göre öz disiplinin ikinci görevine ilişkin stratejiler

\begin{tabular}{ll}
\hline Öz Disiplinin İkinci Görevine İlişkin Stratejiler: & \# katılımcı sayısı \\
Ahlaki duyguların geliştirilmesi & \\
Empati becerilerinin geliştirilmesi & 5 \\
• Başkalarının duygularına odaklanma & \\
Sorumlulukla ilgili becerilerin geliştirilmesi & 4 \\
$\bullet \quad$ Sosyal sorumluluk & \\
• Sorumluluk verme & \\
• Ahlaki sorumluluk & \\
\hline
\end{tabular}

Başa çıkma becerilerinin geliştirilmesi, öz disiplin görevlerinin üçüncü alt temasıdır (Tablo 5). Bunu başarmak için, katılımcı öğretmenler bir durumu değiştirebilecekleri inancını geliştirerek çocukları güçlendirmeye (iki öğretmen); çocukların duygularını etkili bir şekilde ifade etmelerine yardımcı olmaya (üç öğretmen); ve zorluklarla karşılaştıklarında çocukları uygun stratejiler geliştirmeleri için güçlendirmeye (bir öğretmen) odaklanmışlardır. Dahası, bir öğretmen ebeveynlerin rolünden bahsetmiş ve diğer bir öğretmen ise kurdukları ilişkilerin rolünü ifade etmiştir.

Tablo 5. Okul öncesi öğretmenlerine göre öz disiplinin üçüncü görevine ilişkin stratejiler 
Öz Disiplinin Üçüncü Görevine İlişkin Stratejiler:

\# katılımcisayıs1

Başa çıkma becerilerinin geliştirilmesi

Bir durumu değiştirebilecekleri inancını geliştirerek çocukları güçlendirme 2

Çocukların duygularını etkili bir şekilde ifade etmelerine yardımcı olma 3

Zorluklarla karşılaştıklarında çocukları uygun stratejiler geliştirmeleri için 1

güçlendirme

Ebeveynlerin rolü

Kurdukları ilișkilerin rolü

Öz disiplin görevlerinin son alt teması olarak öz kontrolün geliştirilmesi ortaya çıkmıştır (Tablo 6). Katılımcı öğretmenler, bazı tekniklerden bahsederek bu alt temayı uygulanabilir hale getirdiklerini belirtmişlerdir: davranışlarını kontrol etmeleri için destek sağlama (tüm öğretmenler); duygularını kontrol etmeleri için destek sağlama (tüm öğretmenler); bağımsız çalışma (bir öğretmen) ve başladığı işi bitirme (tüm öğretmenler). Ayrıca, duygularını kontrol etmelerini desteklemek için bazı öfke yönetimi teknikleri önermişlerdir: zaman verme, çocuğun dikkatini başka bir etkinliğe yönlendirme, vb.

Tablo 6. Okul öncesi öğretmenlerine göre öz disiplinin dördüncü görevine ilişkin stratejiler

Öz Disiplinin Dördüncü Görevine İlişkin Stratejiler: \# katılımcı sayısı

Öz kontrolün geliştirilmesi

Davranışlarını kontrol etmeleri için destek sağlama 7

Duygularını kontrol etmeleri için destek sağlama 7

Bağımsız çalışma

Başladığg işi bitirme

7

\section{Öz disiplinin önemi}

İkinci araştırma sorusu, erken çocukluk dönemi öğretmenlerinin öz disiplinin önemi hakkındaki algılarıdır. Üçüncü alt tema bu konuyla ilgilidir. Vinyet tartışmaları ve görüşme sorularının cevaplandırılması sürecinde, öğretmenlerin hepsi öz disiplinin önemine vurgu yapmıştır. Buna ek olarak, farklı taraflara ait birçok rolün öz disiplin gelişimi için önemli olduğunu belirtmişlerdir (Tablo 7). Bu roller ebeveynlere (tüm öğretmenler); öğretmenlere (tüm öğretmenler); yöneticilere (iki öğretmen); topluma (beş öğretmen); akranlara (dört öğretmen); ve kültüre (bir öğretmen) aittir. Ayrıca öğretmenler yaş (altı öğretmen) ve zamanın (dört öğretmen) öz disiplin gelişimi için önemli olduğunu belirtmişlerdir.

Tablo 7. Okul öncesi öğretmenlerine göre öz disiplinin önemi

\begin{tabular}{ll}
\hline Öz Disiplinin Önemi & \# katılımcı sayıs1 \\
\hline Ebeveynlere ait roller & 7 \\
\hline
\end{tabular}




\begin{tabular}{ll}
\hline Öğretmenlere ait roller & 7 \\
Yöneticilere ait roller & 2 \\
Topluma ait roller & 5 \\
Akranlara ait roller & 4 \\
Kültüre ait roller & 1 \\
Yaş & 6 \\
Zaman & 4 \\
\hline
\end{tabular}

\section{Okul öncesi öğretmenlerinin öz disiplinin gelişimindeki rollerine ilişkin algıları}

Son araştırma sorusu, okul öncesi öğretmenlerinin öz disiplinin gelişimindeki rollerine ilişkin algılarını bulmayı amaçlamıştır. Katılımcı öğretmenler tarafından belirlenen roller, öz disiplin geliştirme stratejileri olarak kodlanmıştır (Tablo 8). Okul öncesi öğretmenlerine göre öğretmenler öncelikle bir rol model olmalıdırlar (beş öğretmen). Övgü ve ödüllendirme yerine, olumlu pekiştirme kullanmalıdırlar (tüm öğretmenler). Bunlara ek olarak, etkinliklerin planlanması (tüm öğretmenler), etkinlik planlamada kullanılan yöntem ve teknikler (iki öğretmen) ve materyaller (iki öğretmen) etkili şekilde düzenlenmelidir (iki öğretmen). Hem öğrenme ortamı (tüm öğretmenler) hem de sosyal ortamlar (beş öğretmen) uygun şekilde düzenlenmelidir (altı öğretmen). İstenmeyen davranış oluşmadan önce önlenmeli (üç öğretmen); eğer ortaya çıkarsa da tepkisel ve/veya gelişimsel bir temel ile yaklaşılmalıdır (dört öğretmen). Ayrıca, çocuklar çok az kontrol sahibi oldukları stresli durumlarla baş etmeleri için desteklenmelidir (üç öğretmen). Öğretmenler çocuklarla konuşurken dikkate alınması gereken bazı rolleri özetlemişlerdir (üç öğretmen). Bunlardan bazıları, görmezden gelme (dört öğretmen); ben-mesajı verme (bir öğretmen); tutarlı olma (tüm öğretmenler); uyarma (altı öğretmen); olumsuz pekiştirme (tüm öğretmenler) ya da çocuğu kontrol etme (altı öğretmen) gibi öğretmen davranışına odaklanan rollerdir. Bazıları ise ebeveynlerle iletişime geçme (tüm öğretmenler); çocuklara bir problemi sahiplenme ve çözme şansı verme (dört öğretmen) ve istenmeyen davranışlarla başa çıkmak için mola verme (tüm öğretmenler) gibi çocuğu ya da ailesini kapsayan şekildedir. Çocukların stresle ve çok az kontrol sahibi oldukları durumlarla başa çıkmalarını desteklemek için öğretmenler beyin firtınası (bir öğretmen) gibi bazı teknikleri ifade etmiştir. Diğer teknikler; birlikte değerlendirme (dört öğretmen); alternatif çözümleri uygulamaya teşvik etme (üç öğretmen); duyguları ifade etme (iki öğretmen) ve zaman vermedir (bir öğretmen). Duyguyu ifade etmek için Tuna öğretmen dördüncü vinyette şunları söylemiştir: “Çocuğun kendini ifade etme yeteneği gelişecek. Bu durumda çocuk kendini ifade eder, ancak bunu uygun şekilde nasıl yapacă̆ını bilemez, ağlar. Ağlayarak yaparsa, yine kendini ifade etme şekline sahiptir, ama bu yanlış bir yoldur, düzeltmeye çalışırız. Bak, böyle 
yaparsan daha iyi olur... " Aynı vinyet tartışması sırasında çocuğu kontrol etmekten bahseden Ilgaz öğretmense, “Evet, sakin olmazsa kesinlikle ya elini / kolunu tutarak ya da onu kucağıma alarak kavrarım. Çünkü ikimizin de gerçekten sakinleşmesi gerekiyor."

Tablo 8. Okul öncesi öğretmenlerine göre öğretmenlerin öz disiplin gelişimindeki rolü

\begin{tabular}{|c|c|}
\hline Öğretmenlerin Öz Disiplin Gelişimindeki Rolü & $\begin{array}{l}\text { \# } \quad \text { kat1limc1 } \\
\text { sayıs1 }\end{array}$ \\
\hline Bir rol model olma & 5 \\
\hline Olumlu pekiştirme & 7 \\
\hline Programı düzenleme & 2 \\
\hline - Etkinlikleri düzenleme & 7 \\
\hline - Yöntem ve teknikleri düzenleme & 2 \\
\hline - Materyalleri düzenleme & 2 \\
\hline Çevreyi düzenleme & 6 \\
\hline - Öğrenme çevresini düzenleme & 7 \\
\hline - Sosyal çevreyi düzenleme & 5 \\
\hline İstenmeyen davranıș ortaya çıkmadan önce önleme & 3 \\
\hline İstenmeyen davranışla tepkisel ve/veya gelişimsel bir temelle yaklaşma & 4 \\
\hline - Çocukla konuşma & 3 \\
\hline - Görmezden gelme & 4 \\
\hline - Çocuğu kontrol etme & 6 \\
\hline - Uyarma & 6 \\
\hline - Olumsuz pekistirec verme & 7 \\
\hline - Ebeveynlerle iletișime geçme & 7 \\
\hline - Ben mesaiı verme & 1 \\
\hline Tutarliolma & 7 \\
\hline$\bullet \quad$ I utarli olma & 4 \\
\hline $\begin{array}{l}\text { - Çocuklara bir problemi sahiplenme ve çözme şansı verme } \\
\text { - Mola verme }\end{array}$ & $\begin{array}{l}4 \\
7\end{array}$ \\
\hline $\begin{array}{l}\text { Çocukları çok az kontrol sahibi oldukları stresli durumlarla baş etmeleri için } \\
\text { destekleme }\end{array}$ & 3 \\
\hline - Beyin firtınası & 1 \\
\hline - Birlikte değerlendirme & 4 \\
\hline - Alternatif çözümleri uygulamaya teşvik etme & 3 \\
\hline - Duyguları ifade etme & 2 \\
\hline - Zaman verme & 1 \\
\hline
\end{tabular}

\section{Tartışma ve Yorum}

Öz disiplin, evde, okulda, oyunda vb. öğretilebilir bir görev olarak kabul edilir. Deneyimler yoluyla öğrenilebildiği vurgulanmaktadır. Deneyimlerden kast edilen ise kurulan ilişkilerin etkisidir. İlişkiler organizmayı şekillendirir. Yani gelişimi için değil, aynı zamanda çocukların tüm yaşamı için de önemlidir. Öğretmenlerin çocuklarla sınıfta geçirdikleri bir gün boyunca kurdukları karşılıklı ilişkiler, öz disiplin gelişimi için olası fırsatları içerir. Okul öncesi 
sınıflarının oyun temelli, çocuk merkezli ve olumlu ilişki fırsatları sağlayan bir psikolojik ortamı vardır. Bu nedenle, okul öncesi öğretmenlerinin öz disiplin ve gelişimine ilişkin algıları önem taşımaktadır (Bear, 2005: Bennis, 2008; Combs, 1985; Purkey, 1985).

Öz disiplin, öz düzenleme (Bear, 2005; Duckworth, 2009; Duckworth ve Seligman, 2006), özdenetim (Gordon, 1991; Kuhn, 2006) ve sorumlu davranış (Curwin ve Mendler, 1999) gibi çeşitli kavramlarla tanımlanmıştır (Zimmerman ve Kitsantas, 2014). Bu kavramlara ek olarak başka tanımlamalar da yapılmıştır. Bu tanımların ortak noktaları, doğru olanı bilme, yapmayı isteme ve yapma; biri varmış gibi davranma (Bear, 2005; Gordon, 1991); ve dış güçler tarafından kontrol edilmemedir (Coloroso, 2002; Duckworth, 2009). Birbirinin yerine kullanılmasına rağmen, her kavramın kendine özgü bir anlamsal altyapısı vardır (Zimmerman ve Kitsantas, 2014). Bu çalışmanın katılımcıları da bu kavram ve tanımları kullanarak öz disiplini tanımlamışlardır. Bunlara, yeni kavramlar ve anlamlar da eklemişlerdir: kendini ifade etme, kendi kendini örgütleme ve doğruyu yanlıştan ayırma. Elde edilen sonuçlara göre okul öncesi öğretmenleri bu kavramları öz disiplinle ilişkili olarak algılamışlardır. Bu çalışmada öz disiplinle ilişskili buldukları kavramlara ulaşmak amaçlanmış, kendi anlamsal altyapılarıyla ilgili algılarına ulaşmak amaçlanmamıştır. Bu nedenle, ilişkili buldukları kavramların arka plan anlamlarını bilip bilmediklerine dair herhangi bir bilgi alınmamıştır. Planlanacak çalışmalarda, bu konuyu araştırmak faydalı olacaktır.

Öğretmenlerle kurdukları ilişkiler çocuklara önemli mesajlar vermektedir (Coloroso, 2002; Flicker ve Hoffman, 2006; Hamre ve Pianta, 2001; Pianta ve Stuhlman, 2004). Bu mesajlar olumlu duyguları (Bear, 2005; Brooks ve Goldstein, 2007; Coloroso, 2002; Purkey, 1985), ahlaki duyguları (Bear, 2005; Kohn, 2006; Unutkan, 2005), baş etme becerilerini (Bear, 2005); Curwin ve Mendler, 1999); Flicker ve Hoffman, 2006) ve kendi kendini kontrol etme yollarını (Bear, 2005; Curwin ve Mendler, 1999; Duckworth, 2009; Flicker ve Hoffman 2006; Gordon, 1991; Kohn, 2006) yansıtabilir ve yansıtmalıdır. Katılımcı öğretmenlere göre, olumlu duygular öz değer üzerinde etkilidir; günlük yaşamdaki stresli olaylarla etkili başa çıkma becerileri gereklidir; empati ve sorumluluk becerileri ahlaki duygulardır ve sınıf ortamı fiziksel, sosyal ve ahlaki duygu ve davranışları içerir; duyguları ve davranışları kontrol etmek öz disiplinin görevleriyle ilişkilidir. Her ne kadar her biri başlı başına incelenmesi gereken bir konu olsa da araştırma sorularında yer almadığı için her bir konu hakkındaki algıları alınmamıştır. Öz disiplini ima eden mesajlar açısından sınıf uygulamalarının bir resmini çizmek için okul öncesi öğretmenlerinin kullandıkları yolların belirlenmesi gereklidir. 
Verilerin analizi sonucunda katılımcı öğretmenler için öz disiplinin öneminin açık olduğu görülmüştür. Öz disiplinin önemine yaptıkları vurgunun yanı sıra literatürde öz disiplin gelişiminde rolü olduğu vurgulanan bazı kişiler ve oluşumların önemine de vurgu yapmışlardır. Bu kişi ve oluşumlar, ebeveynler ve öğretmenler (Bear, 2005: Bennis, 2008; Combs, 1985; Purkey, 1985), yöneticiler (Bear ve Duquette, 2008), toplum (Rogus, 1985), akranlar (Flicker ve Hoffman, 2006) ve kültürdür (Wayson ve Lasley, 1984). Katılımc1larla paralel olarak literatürde de yaş ve zamanın önemi de (Mischel ve Mischel, 1983) vurgulanmıştır. Literatür incelendiğinde öne çıkan bir diğer faktör ise cinsiyettir. Bu çalışmada katılımcıların cinsiyeti öz disiplin gelişiminde vurgulamış olması dikkat çekicidir. Örneğin bir çalışmada, kızların erkeklerden daha fazla öz disiplin sahibi olduğu görülmüştür (Duckworth ve Seligman, 2006). Öz disiplin gelişiminde doğanın rolüne odaklanan bir çalışmada ise öz disiplinin kızların lehine etkili olduğu bulunmuştur (Taylor, Kuo ve Sullivan, 2002). Hem cinsiyet hem de doğanın rolü okul öncesi öğretmenleri tarafından belirtilmemiş, ancak literatürde etkisi araştırılmış iki faktör olarak karşımıza çıkmaktadır. Her iki faktörle ilgili okul öncesi öğretmenlerinin görüşlerine odaklanan araştırmalar planlanabilir. Toplumsal cinsiyet ile ilgili çalışmalar bu tür farklılıkları açıklayabilir ve toplumların farkındalığını artırmak için bazı önlemler alınabilir. Ayrıca doğa ile ilgili deneyimlerin öz disiplin gelişimindeki önemini ortaya çıkarmak için öğretmenlerle hizmet içi eğitimler geliştirilebilir ve uygulanabilir.

Katılımcılar, öğretmenlerin çocukların yaşamında önemli rolleri olduğunu belirtmiştir. Bu rollerin bir yönünün, bazı stratejiler yoluyla öz disiplin gelişimini desteklemek olduğunu aktarmışlardır ve yedi strateji belirlemişlerdir. Bu stratejiler: rol model olma, övme ve ödüllendirme, programı düzenleme, çevreyi düzenleme, yanlış davranışları önleme, yanlış davranışlarla başa çıkma ve çocukların stresle ve çok az kontrol sahibi oldukları durumlarla başa çıkmalarına yardımcı olmadır. Sosyal Öğrenme Kuramında ilk strateji çok önemli kabul edilmektedir (Bandura, 1977). Teoriye göre çocuklar bir yetişkinden bir davranışı öğrenir, test eder ve yararlı olduğunu düşünürse devam eder. Öte yandan ikinci strateji olan övgü ve ödüllendirme, bir dış güçtür. Bazı yazarlar, çocukların övgüye ve/veya ödüle bağımlı olmalarına ve kendilerini başkalarının gözünden değerlendirmelerine yol açabileceğini belirtmektedir (Bandura; 1977; Bear, 2005; Bear ve Duquette, 2008; Coloroso, 2002; Curwin ve Mendler, 1999; Gordon, 1991; Kohn, 2006). Bu nedenle öğretmenler övgü ve ödüllendirmeyi kullanırken stratejik davranmalı ve nerede-nasıl kullanırsa çocuğun bunlara bağımlı olmayacağı ya da kendilerine ilişkin öz-değerlendirme yapmada olumsuz etkileyebileceği konularında haberdar olmalıdır. Katılımcılar öğrenim programını-günlük 
programı düzenlemeyi üçüncü strateji olarak belirtmişlerdir. Bear'a (2005) göre, etkinliklerin düzenlenmesi öz disiplin gelişimi için etkilidir. Dördüncü strateji olarak katılımcılar çevreyi düzenlemeden bahsetmişlerdir. Curwin ve Mendler (1999), Flicker ve Hoffman (2006) ve Kohn (2006), sadece öğrenme ortamını değil, aynı zamanda sosyal ortamları da düzenlemenin önemini vurgulamaktadırlar. Çocukları sınıfa ait hissettirmek için öğretmenler her iki ortamı da çocukların gelişimlerine uygun olacak şekilde düzenlemelidirler (Scachetti, 1959). Olumsuz davranışları ortaya çıkmadan önce önlemek, katılımcılar tarafından oldukça vurgulanan beşinci strateji olmuştur. Bu strateji aynı zamanda kapsamlı sınıf yönetimi için de önemlidir (Bear, 2005; Combs, 1985; Karaoğlu, 2002). Katılımcı öğretmenler ayrıca öz disiplin gelişimi açısından istenmeyen davranışlarla nasıl başa çıkılacağından bahsetmişlerdir. Tepkisel ve/veya gelişimsel modellere ek olarak, özellikle ilişki-dinleme temelli modelleri de işlevsel olarak vurgulamışlardır. Böylece çocuklar kendilerini farklı yollarla ifade edebileceklerini görebilir ve davranışlarının sonuçlarının farkına varabilirler. Bu farkındalık, yaşamda sorumlu ve disiplinli varlıklar olmak için önemli olarak görülmektedir (Bear, 2005; Bear ve Duquette, 2008; Curwin ve Mendler, 1999; Edwards, 2000; Gordon, 1991; Kohn, 2006). Öz disiplinle ilgili olduğu literatürle desteklenen stratejilerin yanında, katılımcı öğretmenlerin literatürde öz disiplinle ilgili görülmeyen bazı stratejileri de öz disiplinle ilişkilendirdikleri görülmüştür. Bu stratejiler çocuğu kontrol etme, olumsuz pekiştireç verme ve mola vermedir. Bu tür stratejiler, öz disiplin gelişimin desteklemenin aksine bağımlı davranışla sonuçlanacaktır (Bear, 2005; Coloroso, 2002; Curwin ve Mendler, 1999; Gordon, 1991; Kohn, 2006). Bu durumu, Brundrett ve Lungka'nın (2019) çalışma bulguları açıklamaktadır. Öğretmenlerin öz disiplinle ilgili bir algıya sahip olmalarına karşın uygulamaları tam tersi olabilmektedir. Katılımcı öğretmenler son strateji olarak çocukların stres durumlarıyla baş etmelerine yardımcı olmanın altını çizmişlerdir. Kendilerinin farkında olan, yaşamları hakkında güçlü hisseden ve kararları üzerinde öz kontrol hisseden çocuklar daha sorumlu, daha dirençli ve daha disiplinli hale gelecektir (Curwin ve Mendler, 1999).

\section{Sonuç ve Öneriler}

Tüm bu bulgular değerlendirildiğinde, katılımcı öğretmenlerin öz disiplini tanımladıkları; görevlerini belirledikleri; önemi hakkında bilgi sahibi oldukları ve gelişimini desteklemek için kullandıkları stratejileri aktardıkları görülmüştür. Ancak ilgili literatürle uyumlu olmayan stratejiler kullandıkları da fark edilmiştir. Bunlar övme ve ödüllendirme, çocuğu kontrol etme, olumsuz pekiştireç kullanma ve mola vermedir. Bu tür stratejiler, öğretmenlerin kendi eğitim geçmişinden veya kültürel yaklaşımından kaynaklanabilir. 
Öğretmenler, çocukluklarında veya hizmet öncesi öğretmenlik eğitimi sırasında böyle deneyimler yaşamış olabilirler. Dahası, yetiştirildikleri kültürde bu tür çocuk yetiştirme uygulamaları olabilir. Böylece, öğretmenlerin davranışlarını etkileyen faktörler, bu konular hakkında yapılacak araştırmalarla analiz edilebilir. Öğretmenlerin öz disiplin konusunda bilinçlendirilmesi için hizmet içi eğitimler düzenlenebilir. Ayrıca, hizmet öncesi öğretmen yetiştirme ortamları öz disiplin geliştirmeye uygun stratejiler açısından yeniden düzenlenebilir. Bunlara ek olarak, teknoloji kullanımının öz disiplin üzerindeki etkisi araştırılabilir. Öz disiplinin diğer kavramlarla arasındaki benzer ve farklı yönleri belirlenerek ilişkilerine bakılabilir, bir model geliştirme çalışması yapılabilir. Bunların yanında, doğada olma ya da doğayla iletişim-etkileşimin çocuklarda öz disiplin gelişimi üzerine yapılan araştırmalar çoğalabilir. Doğasever olmayla öz disiplin gelişimi arasındaki ilişki araştırılabilir. Her ne kadar katılımcı öğretmenler vurgulamamış olsa da cinsiyetin öz disiplinle ilişkisi incelenebilir. Kültürel faktörler ve/veya toplumsal cinsiyet algılarının öz disiplin üzerindeki rolü de derinlemesine bakılabilir. Anne-baba tutumları ve öz disiplin gelişimi, incelenecek diğer bir araştırma konusu olabilir. Öz disiplinin, pozitif psikolojinin bir parçası (Duckworth ve Seligman, 2006) ve aynı zamanda eğitimde önemli bir faktör (Bear, 2005) olduğu bilgisinden yola çıkılarak insan yaşamının tamamı üzerindeki, hem mutluluk hem başarıdaki belirleyici rolü incelenebilir.

\section{Makalenin Bilimdeki Konumu (Yeri)}

\section{Eğitim, Temel Eğitim, Okul Öncesi Eğitim}

\section{Makalenin Bilimdeki Özgünlüğü}

Makale, yaşamın en önemli dönemi olarak görülen okul öncesi yıllarda, çocukların eğitiminden sorumlu okul öncesi öğretmenlerinin öz disipline ilişkin bakış açılarına ulaşmayı amaçlamıştır. Öz disiplin, literatürde vurgulandığı gibi hem insanların olumlu yönlerine ve gelişimlerine odaklanan pozitif psikoloji bilimi hem de eğitim ortamlarında etkili öğrenmeyi destekleyen sınıf yönetiminin incelendiği eğitim bilimlerinin kesişimindedir. Bu bağlamda, özellikle günümüzde öneminin altı gittikçe daha yoğun şekilde çizilmekte, eğitim ortamlarında öz disipline yapılan vurgu her geçen gün artmaktadır. Böylece, öz disiplinin okul öncesi yıllardan başlayarak eğitim ortamlarında nasıl geliştirilebileceğine ilişkin farkındalık ortaya konulmuştur. Bilimsel literatüre hem günümüz hem de gelecek çalışmalarla ilişkili önemli katkı sağlayacaktır. 


\section{Kaynaklar}

Baerny, M. B. (2006). School-wide expectation plans: A case study of the implementation process in an elementary school (Yayımlanmamış yüksek lisans tezi). Pasific Lutheran University, Tacoma, ABD.

Balat, G. U. (2005). Değerler eğitimi ve değerler eğitimi programları. A. Oktay \& Ö. P. Unutkan (Ed.) Okul öncesi eğitimde güncel konular (s. 197-213) içinde. İstanbul: MORPA Kültür Yayınları.

Bandura, A. (1977). Social learning theory. Englewood Cliffs, N.J.: Prentice-Hall.

Barter, C. \& Renold, E. (2000). - I wanna tell you a storyll: Exploring the application of vignettes in qualitative research with children and young people. International Journal of Social Research Methodology, 3(4), 307-323.

Bear, G. B. (2005). Developing self-discipline and preventing and correcting misbehavior. Boston: Pearson Education.

Bear, G. G., \& Duquette, J. F. (October 2008). Fostering self-discipline. Principal Leadership, 9(2), 10-14.

Bear, G. G., Slaughter, J. C., Mantz, L. S., \& Farley-Ripple, E. (2017). Rewards, praise, and punitive consequences: Relations with intrinsic and extrinsic motivation. Teaching and Teacher Education, 65, 10-20. Doi: https://doi.org/10.1016/j.tate.2017.03.001

Bennis, D. (Summer 2008). Do freedom-based schools fail to produce self- discipline? ENCOUNTER: Education for Meaning and Social Justice, 21(2), 38-40

Brooks, R. \& Goldstein, S. (2007). Raising a self-disciplined child: Help your child become more responsible, confident, and resilient. ABD: McGraw Hill.

Brundrett, M. \& Lungka, P. (2019). The development of teachers' knowledge and behavior in promoting self-discipline: A study of early years teachers in Thailand, Education 3-13, 47(4), 462-474. Doi: 10.1080/03004279.2018.1498996

Carlton, M. P. \& Winsler, A. (1998). Fostering intrinsic motivation in early childhood classrooms. Early Childhood Education Journal, 25 (3), 159-166.

Casey, B. J., Somerville, L. H., Gotlib, I. H., Ayduk, O., Franklin, N. T., Askren, M. K., Jonides, J., Berman, M. G., Wilson, N. L., Teslovich, T., Glover, G., Zayas, V., Mischel, W. \& Shoda, Y. (2011). Behavioral and neural correlates of delay of gratification 40 years later. The Proceedings of the National Academy of Sciences, 108(36), 14998-5003. Doi: 10.5214/ans.0972.7531.180407.

Coloroso, B. (2002). Kids are worth it!. New York: Harper Collins. 
Combs, A. W. (1985). Achieving self-discipline: Some basic principles. Theory into Practice, 24(4), 260- 264.

Committee on Psychosocial Aspects of Child and Family Health (1998). Guidance for effective discipline. Pediatrics, 101(4), 723-728.

Creswell, J. W. (2007). Qualitative inquiry and research design: Choosing among five approaches (2nd ed.). Thousand Oaks, CA: Sage.

Cummings, C. B. (2000). Winning Strategies for Classroom Management. Alexandria: Association for Supervision \& Curriculum Development.

Curwin, R. L. \& Mendler, A. N. (1999). Discipline with Dignity. Alexandria: Association for Supervision \& Curriculum Development.

Diamond, A. (2012). Activities and Programs That Improve Children's Executive Functions. Current Directions in Psychological Science, 21(5), 335-341. Doi: https://doi.org/10.1177/0963721412453722

Diamond, A. \& Lee, K. (2011). Interventions Shown to Aid Executive Function Development in Children 4 to 12 Years Old. Science, 333(6045), 959-964. Doi: 10.1126/science.1204529959-964

Duckworth, A. L. (2009). Self-discipline is empowering. The Phi Delta Kappan, 90(7), 536.

Duckworth, A. L. \& Carlson, S. M. (2013). Self-Regulation and School Success. B. W. Sokol, F. M. E. Grouzet \& U. Müller (Ed.) Self-Regulation and autonomy: social and developmental dimensions of human conduct (s. 208- 230) içinde. New York: Cambridge University Press.

Duckworth, A., \& Gross, J. J. (2014). Self-control and grit: Related but separable determinants of success. Current Directions in Psychological Science, 23(5), 319325. Doi: https://doi.org/10.1177/0963721414541462

Duckworth, A. L. \& Seligman, M. E. P. (2005). Self-discipline outdoes IQ in predicting academic performance of adolescents. Psychological Science, 16(12), 939-944.

Duckworth, A. L. \& Seligman, M. E. P. (2006). Self-discipline gives girls the edge: Gender in self-discipline, grades, and achievement test scores. Journal of Educational Psychology, 98(1), 198-208.

Edwards, C. H. (2000). Classroom discipline and management (3. Basim). New York: John Wiley \& Sons, Inc. All.

Eisenberg, N., Valiente, C., Spinrad, T. L., Cumberland, A., Liew, J., Reiser, M., Zhou, Q., \& Losoya, S. H. (2009). Longitudinal relations of children’s effortful control, impulsivity, 
YYÜ Eğitim Fakültesi Dergisi (YYU Journal of Education Faculty), 2021; 18(1)706-732,http://efdergi.yyu.edu.tr,

and negative emotionality to their externalizing, internalizing, and co-occurring behavior problems. Developmental Psychology, 45(4), 988-1008. Doi: https://doi.org/10.1037/a0016213

Flicker, E. S. \& Hoffman, J.A. (2006). Guiding children’s behavior: Developmental discipline in the classroom. New York: Teachers College Press.

Goldman, S. S. (2006). Self-discipline predicts academic performance among low-achieving adolescents. RES: Journal of Undergraduate Research and Writing, 2(1), 84-97.

Gordon, T. (1991). Discipline that works. New York: Plume.

Gottfried, A. E., Fleming, J. S., \& Gottfried, A. W. (2001). Continuity of academic intrinsic motivation from childhood through late adolescence: A longitudinal study. Journal of Educational Psychology, 93(1), 3-13. Doi: https://doi.org/10.1037/0022-0663.93.1.3

Gottfried, A. E., \& Gottfried, A. W. (1996). A Longitudinal Study of Academic Intrinsic Motivation in Intellectually Gifted Children: Childhood through Early Adolescence. Gifted Child Quarterly, 40(4), 179-183. Doi: https://doi.org/10.1177/001698629604000402

Gottfried, A. E., Gottfried, A. W., Morris, P. E., \& Cook, C. R. (2008). Low academic intrinsic motivation as a risk factor for adverse educational outcomes: A longitudinal study from early childhood through early adulthood. C. Hudley \& A. E. Gottfried (Eds.), Child development in cultural context. Academic motivation and the culture of school in childhood and adolescence (s. 36-69) içinde. Oxford University Press. Doi: https://doi.org/10.1093/acprof:oso/9780195326819.003.0003

Hamre, B. K. \& Pianta, R. C. (2001). Early teacher-child relationships and the trajectory of children's school outcomes through eighth grade. Child Development, 72(2), 625-638.

Hughes, R. \& Huby, M. (2002). The application of vignettes in social and nursing research. Journal of Advanced Nursing, 37(4), 382-386.

Jeffries, C. \& Maeder, D. W. (2004-2005). Using vignettes to build and assess teacher understanding of instructional strategies. The Professional Educator, 27(1-2), 17-28.

Karaoğlu, M. (2002). Okul öncesi eğitim kurumlarında istenmeyen davranışlar ve yönetimi (Yayımlanmamış yüksek lisans tezi). Pamukkale Üniversitesi, Denizli, Türkiye.

Kohn, A. (1996). Beyond discipline: From compliance to community. Alexandria, VA: Association for Supervision and Curriculum Development.

McDonald, W. (October 2015). Is self-discipline the master key to success? Erişim adresi: https://www.linkedin.com/pulse/self-discipline-master-key-success-wayne-mcdonald/ 
YYÜ Eğitim Fakültesi Dergisi (YYU Journal of Education Faculty), 2021; 18(1)706-732,http://efdergi.yyu.edu.tr,

Merriam, S. B. (1998). Qualitative research and case study applications in education. San Francisco: Jossey-Bass Publishers.

Mischel, H. N., \& Mischel, W. (1983). The development of children's knowledge of selfcontrol strategies. Child Development, 54(3), 603-619.

Mischel, W. (2014). The Marshmallow Test: Mastering self-control. New York: Little, Brown and Company.

Moffitt, T. E., Arseneault, L., Belsky, D., Dickson, N., Hancox, R. J., Harrington, H. L., Houts, R., Poulton, R., Roberts, B. W., Ross, S., Sears, M. R., Thomson, W. M. \& Caspi, A. (2011, Şubat). A gradient of childhood self-control predicts health, wealth, and public safety. Proceedings of the National Academy of Sciences, 108(7), 26932698. Doi: 10.1073/pnas.1010076108

Oktay, A. (2005). Okul öncesi dönemde disiplin. A. Oktay \& Ö. P. Unutkan (Ed.), Okul öncesi eğitimde güncel konular (s. 181-188) içinde. İstanbul: MORPA Kültür Yayınları.

Patton, M. Q. (2002). Qualitative research \& evaluation methods (3. Basim). Thousand Oaks, London, New Delhi: Sage.

Pianta, R. C. \& Stuhlman, M. W. (2004). Teacher-child relationships and children's success in the first years of school. School Psychology Review, 33(3), 444-458. Doi: 10.1080/02796015.2004.12086261

Purkey, W. W. (Autumn, 1985). Inviting student self-discipline. Theory into Practice, 24(4), 256-259.

Rogus, J. F. (1985). Promoting self-discipline: A comprehensive approach. Theory into Practice, 24(4), 271-276.

Scachetti, E. F. (1959). Good discipline is self-discipline (Yayımlanmamış yükssek lisans tezi). Newark State College, New Jersey, ABD.

Schoenberg, N. E. \& Ravdal, H. (2000). Using vignettes in awareness and attitudinal research. International Journal of Social Research Methodology, 3(1), 63-74.

Stake, R. E. (2010). Qualitative research: Studying how things work. New York, London: The Guilford Press.

Stolte, J. F. (2001). The context of satisfying in vignette research. The Journal of Social Psychology, 134(6), 727-733.

Tao, T., Wang, L., Fan, C. \& Gao, W. (2014). Development of self-control in children aged 3 to 9 years: Perspective from a dual-systems model. Scientific Reports, 4(7272), 1-5. Doi: $10.1038 /$ srep07272. 
Taylor, A. F., Kuo, F. E. \& Sullivan, W. C. (2002). Views of nature and self-discipline: evidence from inner city children. Journal of Environmental Psychology, 22, 49-63. Doi:10.1006/jevp.2001.0241

Unutkan, Ö. P. (2005). Okul öncesi dönemde sorumluluk eğitimi. A. Oktay \& O. P. Unutkan (Ed.), Okul öncesi eğitimde güncel konular (s.189-196) içinde. İstanbul: MORPA Kültür.

Wayson, W. W. \& Lasley, T. J. (1984). Climates for excellence: schools that foster selfdiscipline. The Phi Delta Kappan, 65(6), 419-421.

Wiener, D. N. \& Phillips, E. L. (1971). Training children in self-discipline and self-control or how to be good parents and teachers without at all times pleasing, indulging, or giving love. ABD: Prentice-Hall International.

Willis, E. (2016). An empathetic beginning in education: exploring the prospects of selfregulation skills on pro-social behaviour in the early childhood environment. Early Child Development and Care, 186(4), 662- 70. Doi: 10.1080/03004430.2015.1045422

Yin R. K. (2009). Case study research: Design and methods (4th ed.). Thousand Oaks: Sage.

Zelazo, P. D. \& Carlson, S. M. (2012). Hot and cool executive function in childhood and adolescence: Development and plasticity. Child Development Perspectives, 6(4), s 354360. Doi: 10.1111/j.1750-8606.2012.00246.x

Zimmerman, B. J. \& Kitsantas, A. (2014). Comparing students' self-discipline and selfregulation measures and their prediction of academic achievement. Contemporary Educational Psychology, 39, 145-155. Doi: https://doi.org/10.1016/j.cedpsych.2014.03.004 


\section{Summary}

\section{Statement of Problem}

Self-discipline is one and an important aspect of character. The term of self-discipline can be summarized as taking responsibility of own behaviors, in other words, controlling them (Tao, Wang, Fan and Gao, 2014; Zimmerman and Kitsantas, 2014). It has been accepted as crucial in everyday lives (Tao, Wang, Fan and Gao, 2014). Many definitions can be made of it (Bear, 2005) and in relation to those definitions, different connections can be found between self-discipline and other constructs (motivation, self-control, self-regulation, executive functions, locus of control, etc.) (Balat, 2005; Bear, 2005; Gordon, 1991; Oktay, 2005). However, it is basically defined by three developmental areas: emotional, social and moral (Bear, 2005); and shows positive long-term effects on both individual and social life. Thus, it can be said that self-discipline is and should be developmental, supportive and collimating. This is the reason why societies give importance to develop self-discipline strategies throughout ages (Bear, 2005; Wiener and Philips, 1971). Moreover, the important and irreversible effects of early childhood years on character are recognized by social and human science societies throughout decades. Therefore, preschool teachers' perceptions of self-discipline, their perceptions of its importance and techniques that they were using become important topics since they are the first professionals in children's lives. Therefore, the aim of this study was to find how preschool teachers perceive their role on self-discipline development of children.

\section{Method}

For current study, qualitative research methodology was found to be appropriate for reaching deeper meanings. To get their perceptions about self-discipline, data from one of a preschool context was collected through implementing case study methodology. Participants of the study were seven teachers working at the same private educational institution in Ankara as preschool teachers. They were below their 30s; were graduated from a pre-school teacher education program of a faculty of education; and had one to six years of teaching experience. For data collection, an interview protocol which was developed based on the observations at two other private preschools. The interview protocol included ten vignettes with three to four related questions for each and eleven interview questions. Before the study, interview protocol was pilot tested with six pre-school teachers. Semi-structured interviews were planned for data collection. Interviews were started after getting their consent. With having ten vignettes discussions and eleven interview questions, each interview took at least one and a half hour. Descriptive analysis technique was used for data analysis. A coding sheet developed during 
pilot study was used for data analysis. Trustworthiness of the study was checked by triangulation of sources and analyst triangulation (Denzin, 1978, as cited in Creswell, 2007; Merriam, 1998; Patton, 2002). Thick description (Merriam, 1998) was used for transferability. In each step of the current study, their rights (e.g. withdrawing if they had no interest, stopping the interview or not answering a specific question) and researchers claim to protect these rights were explained to the participants. Neither their voices nor their data were shared with third parties. No identical information was given and pseudonyms were used instead of their names.

\section{Findings}

After conducting and analyzing interviews with seven teachers, four themes were emerged. They were, definitions of self-discipline, missions of self-discipline, importance of selfdiscipline and strategies for self-discipline development. Early childhood teacher participants defined self-discipline (table 1) and its missions as self-expression (two teachers), self-control (six teachers), self-regulation (four teachers), self-organization (three teachers), knowing what to do (all teachers), separating right from wrong (three teachers), not being controlled by external forces (three teachers), and behaving any situation like somebody exists (four teachers). According to teachers, there were four missions of self-discipline (table 2): development of positive emotions (all teachers; table 3), development of moral emotions (all teachers; table 4), development of coping skills (all teachers; table 5), and development of selfcontrol (all teachers; table 6). Participant teachers pointed out many roles belonging to different parties as being important for self-discipline development (table 7). These roles belonged to parents (all teachers); teachers (all teachers); administrators (two teachers); society (five teachers); peers (four teachers); and culture (one teacher). Age (six teachers) and time (four teachers) were also outlined to be important for self-discipline development. The roles specified by participant teachers were coded as strategies for self-discipline development sub-theme (table 8). According to teachers, they should be a role model (five teachers); instead of praising and rewarding, positive reinforcement should be beneficial (all teachers); curriculum should be arranged (two teachers); both learning (all teachers) and social environments (five teachers) also should be arranged (six teachers); misbehavior should be prevented before occurring (three teachers); if misbehavior occurred it will be dealt with a preventive or corrective base (four teachers); and children should be supported to cope with stress and situations in which they have little control (three teachers). 


\section{Discussion and Conclusion}

Self-discipline has been defined with relevant concepts (Zimmerman and Kitsantas, 2014) which includes self-regulation (Bear, 2005; Duckworth, 2009; Duckworth and Seligman, 2006), self-control (Gordon, 1991; Kuhn, 2006) and responsible behavior (Curwin and Mendler, 1999). In addition to these concepts, some other definitions have been made by participants. Points of that definitions is self-discipline as knowing, desiring and doing the right; behaving like somebody exist (Bear, 2005; Gordon, 1991); and not being controlled by external forces (Coloroso, 2002; Duckworth, 2009). Moreover, they added extra concepts and meanings: self-expression, self-organization, and separating right from wrong.

Relationship with teachers gives important messages to children (Coloroso, 2002; Flicker and Hoffman, 2006; Hamre and Pianta, 2001; Pianta and Stuhlman, 2004). These messages may and should reflect positive emotions (Bear, 2005; Brooks and Goldstein, 2007; Coloroso, 2002; Purkey, 1985), moral emotions (Bear, 2005; Kohn, 2006; Unutkan, 2005), coping skills (Bear, 2005; Curwin and Mendler, 1999); Flicker and Hoffman, 2006) and the ways of self-control (Bear, 2005; Curwin and Mendler, 1999; Duckworth, 2009; Flicker and Hoffman 2006; Gordon, 1991; Kohn, 2006). According to participant teachers, positive emotions had effect on self-worth; effective coping skills with stressful events in daily life were necessary; empathy and responsibility skills were moral emotions and the classroom environment included physical, social and moral emotions and behaviors; and controlling emotions and behaviors were related to the missions of self-discipline.

Importance of self-discipline was clear for participant teachers. In addition to its importance, they specified important roles of different parties like parents and teachers (Bear, 2005: Bennis, 2008; Combs, 1985; Purkey, 1985), administrators (Bear and Duquette, 2008), society (Rogus, 1985), peers (Flicker and Hoffman, 2006), and culture (Wayson and Lasley, 1984). In parallel to participants, importance of age and time (Mischel and Mischel, 1983) were also stressed out in the literature. The role of nature, on the other hand, was found to have effect on self-discipline in favor of girls (Taylor, Kuo and Sullivan, 2002). Additionally, the role of gender regarding to self-discipline was also searched and it was found that girls were more selfdisciplined than boys as stated in another study. (Duckworth and Seligman, 2006). Participant teachers did not mention about the roles of gender and nature.

According to the participants, teachers had important roles to support self-discipline development through some strategies on children's lives. The first strategy is accepted as crucial in Social Learning Theory (Bandura, 1977). The praising and rewarding, the second strategy is 
an external force. Some authors claim that it may result in children being praise- and/or rewarddependent and evaluating themselves from others’ eyes (Bandura; 1977; Bear, 2005; Bear and Duquette, 2008; Coloroso, 2002; Curwin and Mendler, 1999; Gordon, 1991; Kohn, 2006). Arranging curriculum was the third strategy that participants mentioned. According to Bear (2005), arranging activities is efficient for self-discipline development. Environment arrangement is the fourth strategy that participants claimed to use. Curwin and Mendler (1999), Flicker and Hoffman (2006), and Kohn (2006) stressed out the importance of arranging not only learning but also social environments. Preventing misbehavior before it occurs was fifth strategy which was highly recognized by the participants. It is also important for comprehensive classroom management (Bear, 2005; Combs, 1985; Karaoğlu, 2002). Participant teachers also mentioned about how to deal with misbehaviors in terms of self-discipline development. They stressed out more of preventive or corrective models, specifically relationship-listening base as being functional. This is important to become responsible and self-disciplined beings in life (Bear, 2005; Bear and Duquette, 2008; Curwin and Mendler, 1999; Edwards, 2000; Gordon, 1991; Kohn, 2006). Participant teachers, however, outlined some strategies which were not in relation to self-discipline. These strategies were controlling the child, giving negative reinforcement and time-out. Such strategies would result in dependent behavior (Bear, 2005; Coloroso, 2002; Curwin and Mendler, 1999; Gordon, 1991; Kohn, 2006) and this is irrelevant with their self-discipline definitions.

The factors affecting teachers' behaviors may be analyzed by conducting future research about these topics. To make teachers become aware of self-discipline, in-service trainings may be organized. In addition, pre-service teacher training environments might be reorganized in terms of suitable strategies for self-discipline development. 